\title{
PITX3 mutations associated with autosomal dominant congenital cataract in the Chinese population
}

\author{
ZEHUA WU ${ }^{1,2^{*}}$, DELONG MENG ${ }^{1,2^{*}}$, CHENGBO FANG $^{3}$, JIAN LI $^{4}$, XIUJIE ZHENG $^{1,2}$, JIANSUO LIN $^{1,2}$, \\ HAIJIANG ZENG ${ }^{5}$, SIHAN LV ${ }^{4}$, ZHENNING ZHANG ${ }^{6}$, BING LUAN ${ }^{4}$, ZILIN ZHONG $^{1,2}$ and JIANJUN CHEN ${ }^{1,2}$ \\ ${ }^{1}$ Department of Ophthalmology, Shanghai Tenth People's Hospital and Tongji Eye Institute; \\ ${ }^{2}$ Department of Medical Genetics, Tongji University School of Medicine, Shanghai 200092; ${ }^{3}$ Department of Ophthalmology, \\ The First Affiliated Hospital of Anhui Medical University, Hefei, Anhui 230032; ${ }^{4}$ Department of Endocrinology, \\ Shanghai Tenth People's Hospital and Tongji Eye Institute, Tongji University School of Medicine, Shanghai 200092; \\ ${ }^{5}$ Department of Pediatrics, Ganzhou People's Hospital, Ganzhou, Jiangxi 341000; ${ }^{6}$ Translational Medical Center for \\ Stem Cell Therapy and Institute for Regenerative Medicine, Shanghai East Hospital, Shanghai Key Laboratory of Signaling \\ and Disease Research, School of Life Science and Technology, Tongji University, Shanghai 200092, P.R. China
}

Received May 28, 2018; Accepted January 15, 2019

DOI: $10.3892 / \mathrm{mmr} .2019 .9989$

\begin{abstract}
The present study aimed to identify the disease-causing gene of a four-generation Chinese family affected with congenital posterior subcapsular cataracts (CPSC), to additionally investigate the frequency of paired like homeodomain 3 (PITX3) mutations in Chinese patients with autosomal dominant congenital cataract (ADCC) and to analyze the pathogenesis of the mutations identified in the present study. Whole exome sequencing (WES) was utilized to identify the genetic cause of CPSC in the four-generation family. Sanger sequencing was performed to verify the WES results and to screen for mutations of the PITX3 gene in probands of an additional 194 Chinese ADCC families. Co-segregation analysis was performed in the family members with available DNA. Subcellular localization analyses and transactivation assays were performed for the PITX3 mutations identified. From the WES data, the c.608delC (p.A203GfsX106) mutation of PITX3 was identified in the four-generation family with CPSC. A second PITX3 mutation c.640_656del (p.A214RfsX42) was detected in two of the additional 194 ADCC families and one of these two families
\end{abstract}

Correspondence to: Dr Zilin Zhong or Professor Jianjun Chen, Department of Ophthalmology, Shanghai Tenth People's Hospital and Tongji Eye Institute, Tongji University School of Medicine, Medical School Building, 1239 Siping Road, Yangpu, Shanghai 200092, P.R. China

E-mail: zhong_email@sina.com

E-mail: chenjianjun@tongji.edu.cn

${ }^{*}$ Contributed equally

Key words: autosomal dominant inheritance, congenital cataract, paired like homeodomain 3 gene, mutation exhibited incomplete penetrance. Functional studies indicated that these 2 PITX3 mutant proteins retained a nuclear localization pattern, but resulted in decreased transactivation activity, similar to other previously identified PITX3 mutations. In the present study, 2 different mutations (p.A203GfsX106 and p.A214RfsX42) in PITX3 were identified as the causative defect in a four-generation family with CPSC and two ADCC families, respectively. The prevalence of PITX3 gene-associated cataract was $1.54 \%$ (3/195) in the Chinese congenital cataract (CC) family cohort. In vitro functional analyses of these 2 PITX 3 mutations were performed, in order to enhance understanding of the pathogenesis of CC caused by PITX3 mutations.

\section{Introduction}

A cataract is the loss or decrease of vision due to opacification of the lens. At present, cataracts, which account for $50 \%$ of cases of blindness in low- and middle-income countries, are the most common ophthalmic diseases $(1,2)$. Congenital cataract (CC) refers to a lens opacity present at birth, responsible for $10-30 \%$ of all vision loss in infants worldwide (3). In industrialized countries, the occurrence of $\mathrm{CC}$ is $1-6$ cases per 10,000 births, whereas in China it is $\sim 5$ per 10,000 births (4).

$\mathrm{CC}$ with or without other systemic abnormalities is clinically and genetically heterogeneous. At present, at least 50 genes and loci have been demonstrated to be associated with inherited cataract, including crystalline proteins, lens cytoskeletal proteins, membrane junction proteins [including lens fiber major intrinsic protein (MIP)], trans-membrane proteins [including LEM domain-containing protein 2 (LEMD2)], transcription factors [including paired like homeodomain 3 (PITX3), forkhead box protein E3 (FOXE3), transcription factor Maf (MAF), paired box protein Pax-6 (PAX6) and eyes absent homolog 1 (EYA1)] and other functionally associated genes [including FYVE and coiled-coil domain-containing protein 1 (FYCO1), wolframin and transient receptor potential 
cation channel subfamily $M$ member 3] (5). Mutations in PITX3 have been demonstrated to be associated with isolated $\mathrm{CC}$ and CC with anterior segment dysgenesis (ASD) (6).

In the present study, whole exome sequencing (WES) was performed to identify the molecular defects of a four-generation Chinese family with CC. A PITX3 variant (c.608delC) was identified to lead to the development of congenital posterior subcapsular cataract, which was confirmed by slit lamp exam on the proband in family 10003 . The CC caused by PITX3 mutations in an additional 194 Chinese families with $\mathrm{CC}$ were also investigated. A second PITX3 mutation (c.640_656del) identified in family 10094 and 10178 was confirmed to follow an autosomal dominant inheritance pattern, which was in contrast to the autosomal recessive pattern initially described when it was identified in Saudi Arabia in 2011 (7). Furthermore, the in vitro functional studies of these two PITX3 mutations performed in the present study demonstrated comparable molecular consequences for these and other PITX3 mutations, and the results are closely coincided with the hypothesis that these mutations may affect transactivation of PITX3.

\section{Materials and methods}

Patients and clinical data. To search for a new locus for CC, 195 CC families originating from 15 different provinces throughout China (Hunan, Jilin, Guangdong, Guangxi Zhuang Autonomous Region, Hebei, Shanghai, Shanxi, Sichuan, Anhui, Hubei, Liaoning, Jiangxi, Jiangsu, Zhejiang and Beijing) were recruited in the present study. Informed consent was gained directly from the participants, and the study was approved by the Institutional Review Board of The Tongji Eye Institute of Tongji University School of Medicine (Shanghai, China) and adhered to the tenets of the Declaration of Helsinki. The clinical data of the patients were gathered using slit lamp examination. Total genomic DNA was extracted and isolated from peripheral blood $(5 \mathrm{ml})$ using DNA extraction kits (Tiangen Biotech Co., Ltd., Beijing, China).

WES and bioinformatic analysis. In Family 10003 (laboratory reference number), genomic DNA from 2 patients (IV:2 and IV:5) and a selected control (III:3) were analyzed using WES by Genesky Bio-Tech Co., Ltd., (Shanghai, China). Whole-exome trapping was performed using the Agilent SureSelect Human All Exon kit V6 (57Mb; Agilent Technologies, Inc., Santa Clara, CA, USA). The entire protocol, including construction of a shotgun library, in-solution hybridization, washing and capture, was performed according to the manufacturer's protocol. The captured DNA library was then sequenced via Hiseq 2000 platform (2X150 bp) (Illumina, Inc., San Diego, CA, USA), where each sample was provided an average coverage depth of $\sim 150$ reads. Data were aligned to the human genome reference assembly (UCSC Genome Browser hg19) (8) with the Burroughs-Wheeler Aligner. Databases including 1000 Genomes Project, dbSNP137, 1000G_ASN and esp6500si_all were used to filter the variants. The analyses of single-nucleotide variants and indels were performed using the Genome Analysis Toolkit (version 2.4-9 of GATK) The WES data of structural variants and copy-number variations were also assessed. Integrative Genomics Viewer (9) and
CoNIFER (version 0.2.2; http://conifer.sourceforge.net/index. $\mathrm{html}$ ) were used to analyze the bioinformatic prediction based on the BAM files.

Co-segregation analysis and mutation detection. To confirm whether the disease phenotype was co-segregated with the candidate gene in the family 10003 and to screen for PITX3 mutations in probands of an additional 194 Chinese CC families in the exon 4 of PITX3, DNA samples from the members of the four-generation family and $194 \mathrm{CC}$ families were amplified using polymerase chain reaction (PCR). The following primers were used to screen for the PITX3 mutation: PITX3_EXON2 Forward (F), AGAGAACCTCTCAGC ATGCAC; PITX3_EXON2 Reverse (R), AAGCCAGCGCAT ATTCTCC; PITX3_EXON3 F, GGTGCAGGACATAAC AGCTTC; PITX3_EXON3 R, GGACAGTAGGATGGGGTT GAG; PITX3_EXON4 F, CGTCTCTAGCCACCTCATCTC; PITX3_EXON4 R, TCCCTGTTCCTGGCTTTAGTC. Each reaction mixture $(25 \mu \mathrm{l})$ contained $40 \mathrm{ng}$ genomic DNA, 2X Taq Master Mix (Tiangen Biotech Co., Ltd.), $0.5 \mu \mathrm{M}$ forward primer and $0.5 \mu \mathrm{M}$ reverse primer. The PCR thermocycler conditions were as follows: $95^{\circ} \mathrm{C}$ for $3 \mathrm{~min}$; followed by 15 cycles of $95^{\circ} \mathrm{C}$ for $30 \mathrm{sec}, 64-57^{\circ} \mathrm{C}$ for $30 \mathrm{sec}$ (annealing temperature decreased $0.5^{\circ} \mathrm{C}$ each cycle) and $72^{\circ} \mathrm{C}$ for $1 \mathrm{~min}$, then 25 cycles of $95^{\circ} \mathrm{C}$ for $30 \mathrm{sec}, 57^{\circ} \mathrm{C}$ for $30 \mathrm{sec}$ and $72^{\circ} \mathrm{C}$ for $1 \mathrm{~min}$, followed by a final extension at $72^{\circ} \mathrm{C}$ for $10 \mathrm{~min}$. Finally, the PCR products were sequenced using an ABI3730 Automated Sequencer (Applied Biosystems; Thermo Fisher Scientific, Inc., Waltham, MA, USA) and compared with the reference sequence in the National Center for Biotechnology Information database (http://www.ncbi.nlm.nih.gov/).

\section{Functional characterization of PITX3 mutations}

Plasmid constructs and cell culture. The cDNA of the PITX3 wild-type (WT) was synthesized by Sangon Biotech Co., Ltd., (Shanghai, China), and the following primers were used to construct PITX3 WT and mutant plasmids: PTIX3-WT F, GCGAAGCTTATGGAGTTCGGCCTGCTCAG; PTIX3-WT R, CGCGGATCCCTACGGGCGGGGCCGCTC ATA; PITX3-c.608delC overlap F primer, CTCCGCCGC GGCTGCCCCGGGCACCGT; PITX3-c.608delC overlap R primer, GGGCAGCCGCGGCGGAGGGCACCATGGAGG C; PITX3-c.640_656del overlap F primer, ACCGTGCCA GGGCCTGGGCGGGGGC; PITX3-c.640_656del overlap R primer, CCCCGCCCAGGCCCTGGCACGGT. Then, PCR products from the cDNA were inserted into the NheI-high fidelity (HF)- and BamH I-HF-digested pcdna3.1-N-3xflag vector (Invitrogen; Thermo Fisher Scientific, Inc.) to produce the pcdna3.1-N-3x flag-PITX3-WT, pcdna3.1-N-3xflag-PITX 3-c.640_656del. and pcdna3.1-N-3xflag-PITX3-c.608delC expression plasmids. The recombinant plasmids included an $\mathrm{N}$-terminal three tandem FLAG-tag insertion followed by the PITX3 WT or mutant sequences. The luciferase reporter plasmids pGL3-MIP (+58/-598), pGL3-FOXE3 (-2988/-3722) and pGL3-LEMD2 (-77/-985) were constructed by inserting 3 non-coding sequences containing bicoid binding sites from MIP (a 656-bp fragment containing 597-bp of upstream and 59-bp of downstream sequence from human MIP transcriptional start site), FOXE3 (a 735-bp fragment derived from -2988 to -3722 of human FOXE3 promoter) and LEMD2 (a 
908-bp fragment region from-77 to-985 of human LEMD2 promoter) into the XhoI-HF- and HindIII-HF-digested pGL3-Basic vector (Promega Corporation, Madison, WI, USA) separately. Primers designed for luciferase reporter gene plasmid construction were as follows: MIP_+58 to $-598 \mathrm{~F}$, GCACTCGAGAGCCAGACGCAGCAGAACTAT; MIP_+58 to -598 R, GCAAAGCTTGCTGATCGCAGTTCCCACAT; FOXE3_-2988 to -3722 F, GCACTCGAGCCCTACCCCATG TTCCTTGC; FOXE3_-2988 to -3722 R, GCAAAGCTTGCG CCATGATGGGAAGGTCG; LEMD2_-77 to -985 F, GCA CTCGAGCTGCAAAGATGTGGGTTAAG; LEMD2_-77 to -985 R, GCAAAGCTTGCGCCATGATGGGAAGGTCG. Finally, all the constructs were verified by Sanger sequencing. HeLa and 293T cells (American Type Culture Collection, Manassas, VA, USA) were cultured in Dulbecco's modified Eagle medium (Invitrogen; Thermo Fisher Scientific, Inc.), supplemented with $10 \%$ fetal bovine serum (FBS; Invitrogen; Thermo Fisher Scientific, Inc.) and cultured in humidified air containing $5 \% \mathrm{CO}_{2}$ at $37^{\circ} \mathrm{C}$.

Western blot analysis. Following $36 \mathrm{~h}$ transfection with the PITX3 wild-type and mutants plasmids 293T cells were lysed by radioimmunoprecipitation assay lysis buffer (P0013B; Beyotime Institute of Biotechnology, Haimen, China) including a proteinase inhibitor cocktail (Thermo Fisher Scientific, Waltham, MA, USA) on ice. Then, cells were lysed for $2 \mathrm{~h}$ and centrifugated to obtain the supernatant. For western blotting, total protein was quantified using a bicinchoninic acid assay (cat. no. P0010S, Beyotime, Shanghai, China) and $20 \mu \mathrm{g}$ protein/lane was analyzed by means of $12 \%$ SDS-PAGE followed by transfer onto a polyvinylidene fluoride membrane. To avoid non-specific binding, the membranes were blocked with $5 \%$ non-fat milk at $25^{\circ} \mathrm{C}$ for $1 \mathrm{~h}$. Following blocking, the PITX3-FLAG recombinant proteins were detected with an anti-FLAG mouse monoclonal antibody (1:1,000; cat. no. F1804; Sigma-Aldrich; Merck KGaA, Darmstadt, Germany) at $25^{\circ} \mathrm{C}$ for $2 \mathrm{~h}$. The secondary antibody used was Goat Anti-Mouse IgG, HRP-Conjugated (1:5,000; cat. no. CW0102; Beijing CWBio, Beijing, China) at $25^{\circ} \mathrm{C}$ for $1 \mathrm{~h}$. Membranes were visualized by electro chemiluminescent Western Blotting Substrate (cat. no. 10026691, Bio-Rad Laboratories, Inc., Hercules, CA, USA) with Tanon Imaging System (Tanon-5200; Tanon Science \& Technology Co. Ltd., Shanghai, China).

Immunofluorescence. HeLa cells were plated onto coverslips in 12 -well plates and seeded at $2 \times 10^{4}$ cells per well in DMEM with $10 \%$ FBS for $24 \mathrm{~h}$. Cells were transfected with $1.5 \mu \mathrm{g}$ of PITX3 wild-type and mutants plasmids respectively using transfection reagent Vigofect (Vigorous Biotechnology, Inc., Beijing, China) and harvested $24 \mathrm{~h}$ post-transfection. According to the manufacturer's protocol. The cells were washed with PBS 3 times, fixed with purity methanol (100\% methanol) at $-20^{\circ} \mathrm{C}$ for $10 \mathrm{~min}$, permeabilized with $0.25 \%$ Triton $\mathrm{X}-100$ at $25^{\circ} \mathrm{C}$ for $10 \mathrm{~min}$, blocked with $1 \%$ bovine serum albumin (Sangon Biotech Co., Ltd., Shanghai, China) at $25^{\circ} \mathrm{C}$ for $1 \mathrm{~h}$, and incubated with a primary antibody PITX3 (N-20) (cat. no. sc-19307; Santa Cruz Biotechnology, Inc., Dallas, TX, USA) at a $1: 1,000$ dilution at $25^{\circ} \mathrm{C}$ for $1 \mathrm{~h}$. Following washing 3 times with PBS, the cells were subsequently incubated with secondary antibody Alexa Fluor 594 Donkey anti-Goat IgG at a 1:200 dilution (cat. no. A11058; Thermo Fisher Scientific, Inc.) for $1 \mathrm{~h}$ at $25^{\circ} \mathrm{C}$. Nuclei were counterstained with DAPI dye $(0.5 \mu \mathrm{g} / \mathrm{m} 1)$ for $1 \mathrm{~min}$ at $25^{\circ} \mathrm{C}$. Finally, the location of PITX3 wild-type and mutants protein was detected by confocal fluorescent microscopy at two different magnifications: x20 and $\mathrm{x} 40$.

Luciferase assays. 293T cells were plated in 24-well plates and transfected using transfection reagent Vigofect with $75 \mathrm{ng}$ reporter plasmid and luciferase reporter vectors MIP-pGL3, FOXE3-pGL3 and LEMD2-pGL3 (a candidate target gene of PITX3) Each co-transfection included $62.5 \mathrm{ng}$ effector plasmid (PITX3 WT and mutants expression constructs, the total DNA amount was kept the same in all transfections by adding empty pcDNA3.1 vector when required) and $75 \mathrm{ng} \beta$-galactosidase vector, which was used as an internal control for efficiency of transfection. Cells were harvested after $26 \mathrm{~h}$ and luciferase assays were performed as previously described (10).

Statistical analysis. Data represents as means \pm standard error of the mean from 3 experiments performed in quadruplicate. Statistical significance was determined using one-way analysis of variance and Šidák's multiple comparisons test for the comparison of multiple groups using GraphPad Prism v6 software (GraphPad Software, Inc., La Jolla, CA, USA).

\section{Results}

Clinical data. Family 10003 is a large four-generation family with 7 patients with CC ( 2 of them are deceased) demonstrating an autosomal dominant pattern of inheritance (Fig. 1A). In the present study, WES was conducted to map the causative gene for this family. Following identification of the mutation and informing the family of the result of the diagnosis, it was identified that all patients in this family had a primary diagnosis of congenital subcapsular cataract based on clinical descriptions. Therefore, it was considered necessary to confirm the type of cataract via careful ophthalmic examination. Following numerous contacts with members of this family, permission was granted from a patient who had not undergone cataract surgery, and the clinical images were finally obtained (Fig. 1A. In family 10094, the transmission of the CC pathogenic gene from the affected mother to her daughter in an autosomal dominant manner was observed, while in the family 10178, it was verified that the mutation that caused the $\mathrm{CC}$ of the proband was transmitted from the asymptomatic mother, which may indicate that the mode of inheritance is autosomal dominant with decreased penetrance (Fig. 1B). As all patients in these two families had undergone cataract surgery, the types of cataracts present were not able to be identified.

Mutation analysis and co-segregation analysis: In family 10003, WES was performed on 3 individuals (III: 3, IV:2 and IV:5) and a PITX3 variant c.608delC (p.A203GfsX106) in exon 4 was identified, which lead to the substitution of alanine into glycine at residue 203. This deletion mutation resulted in a frameshift in codon 203 and produced an aberrant protein with 106 erroneous residues (Fig. 1C). In the probands of family 10094 and family 10178, Sanger sequencing was performed to investigate the coding mutations in the exon 4 of PITX3 

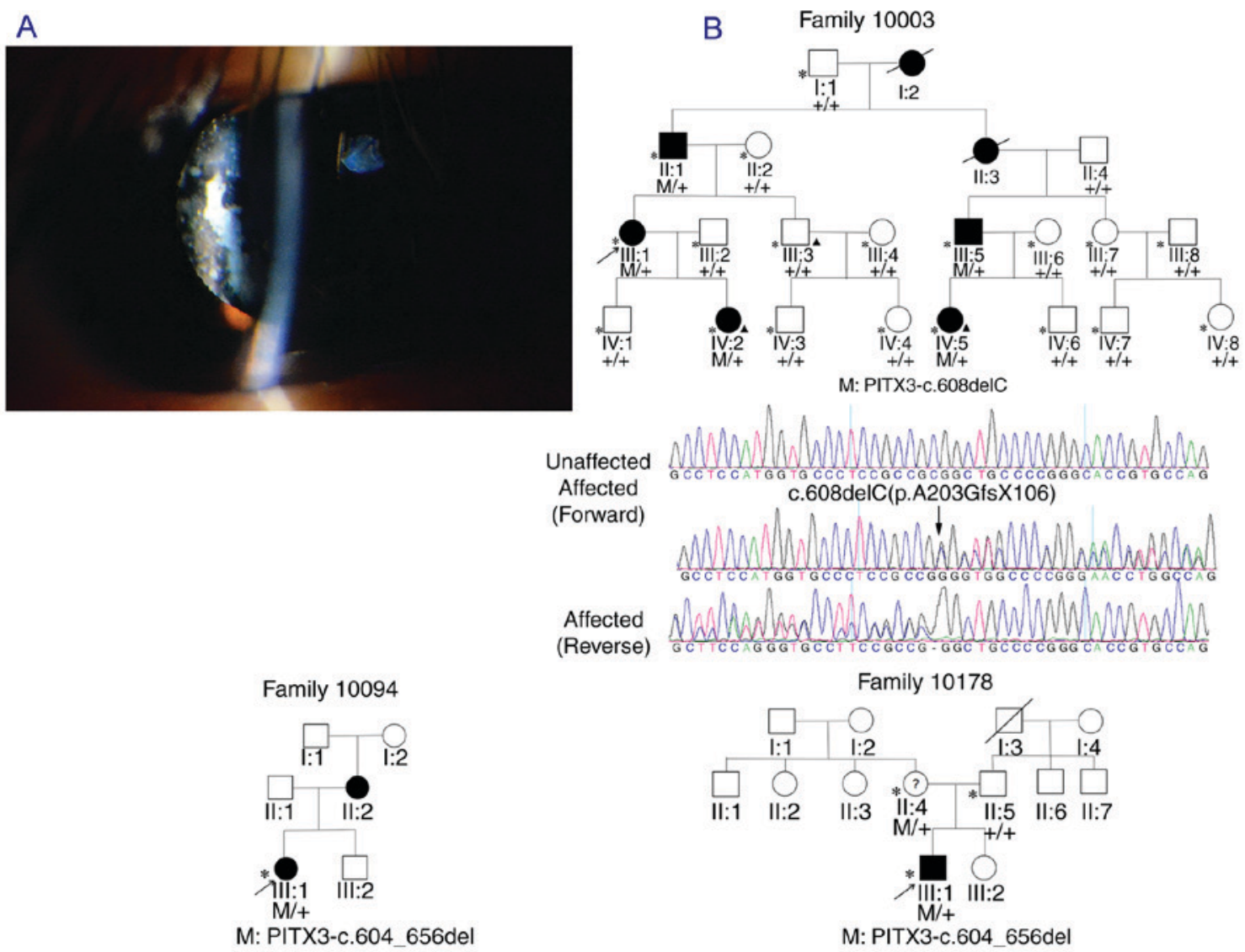

(Reverse)
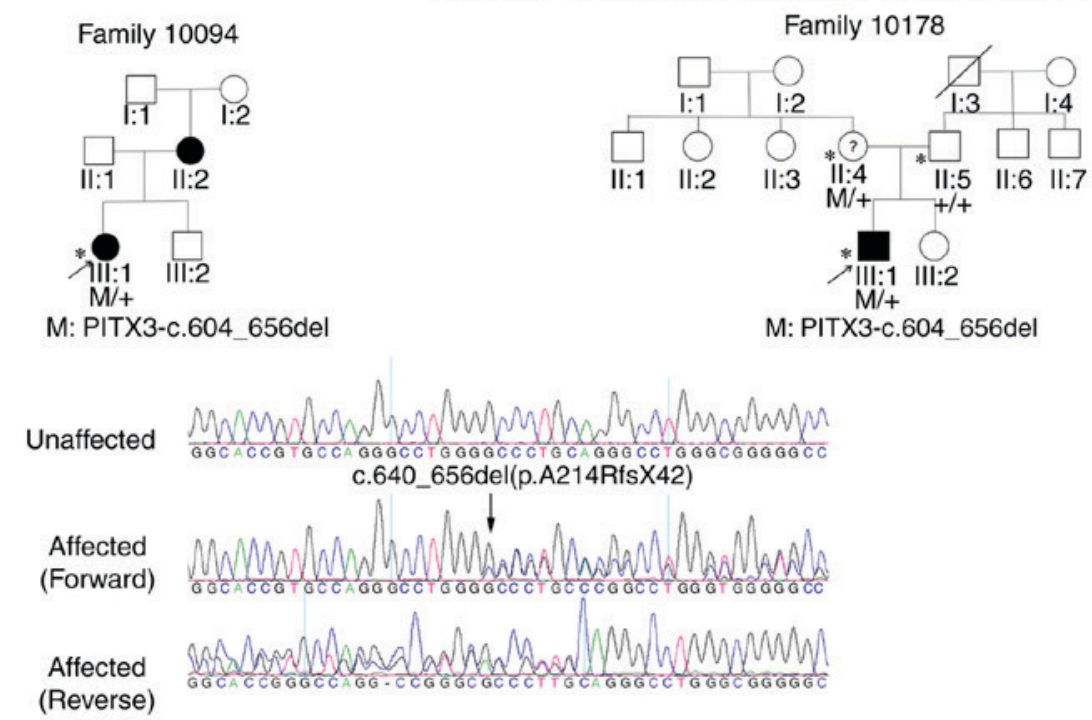

C

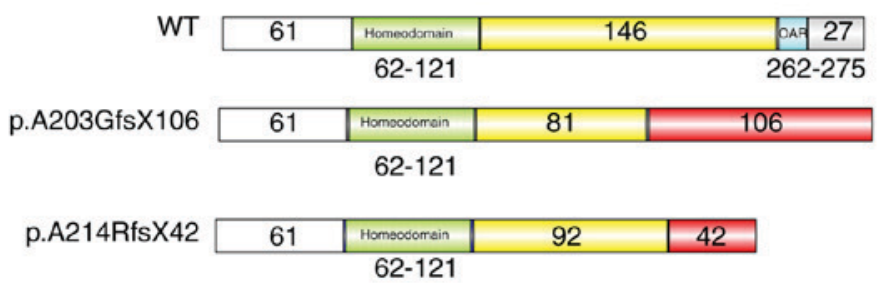

Figure 1. Pedigrees and sequence electropherograms of PITX3 mutations in 3 Chinese families with autosomal dominant congenital cataract. (A) The slit lamp photo of the right eye of the proband in Family 10003. Opacities were exhibited predominantly in the posterior capsule. (B) Pedigrees and sequence electropherograms of PITX3 mutations identified in 3 Chinese CC families. Family 10003 is a four-generation family with PSC. Families 10094 and 10178 are three-generation CC families. Individuals who underwent whole-exome sequencing are marked with triangle and individuals with available DNA samples were marked with asterisk. Probands are indicated by arrow in each pedigree. The black filled shapes signify individuals with cataract conditions, and the oblique line denotes the individuals who have succumbed. The question mark represents the individual identified to carry an asymptomatic mutation. Vertical arrows indicate the mutations in the index patients, respectively. (C) Schematic representation of PITX3 WT and mutated proteins. The green box represents the homeodomain of 60 amino acids and the blue box is the OAR domain of 14 amino acids. The aberrant protein segments caused by mutations are highlighted by the red box. CC, congenital cataract; M, mutant allele; +/WT, wild-type allele; OAR, homeobox protein orthopedia, Aristaless related homeobox and Retinal homeobox protein Rx domain.

gene: An additional PITX3 variant c.640_656del was identified, which resulted in an alanine to arginine substitution at residue 214 (A214RfsX42) and led to a truncation of the PITX3 protein (Fig. 1C). The co-segregation of these two mutations with diseases was demonstrated in the corresponding families with available DNA (Fig. 1A).
Subcellular localization. The PITX3 WT and mutant proteins in the present study were overexpressed in HeLa cells and detected by immunofluorescence (Fig. 2A). The intracellular localization of PITX3 mutants c.608delC (p.A203GfsX106) and c.640_656del (p.A214RfsX42) in the present study were identified to be targeted to the nucleus, which was similar to the PITX3 WT. 
A
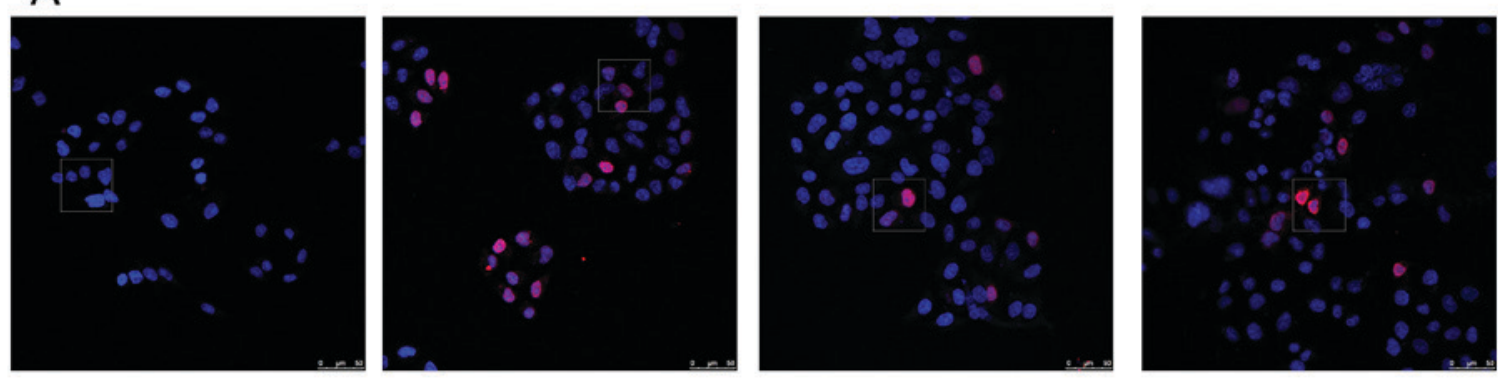

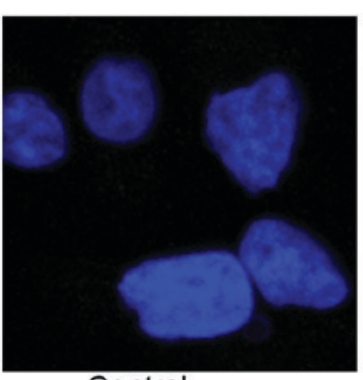

Control

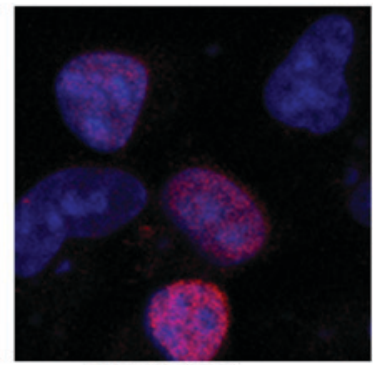

PITX3-WT

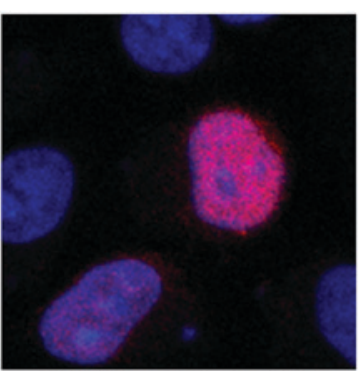

PITX3-c.640_656del

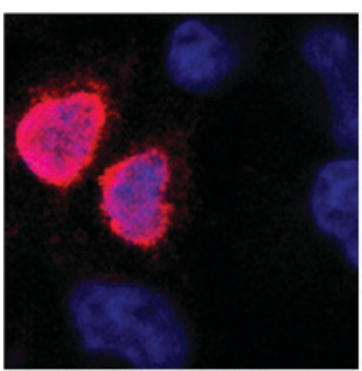

PITX3-c.608delC

B

WT Ala214fs Ala203fs

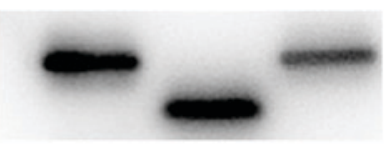

$\beta$-actin
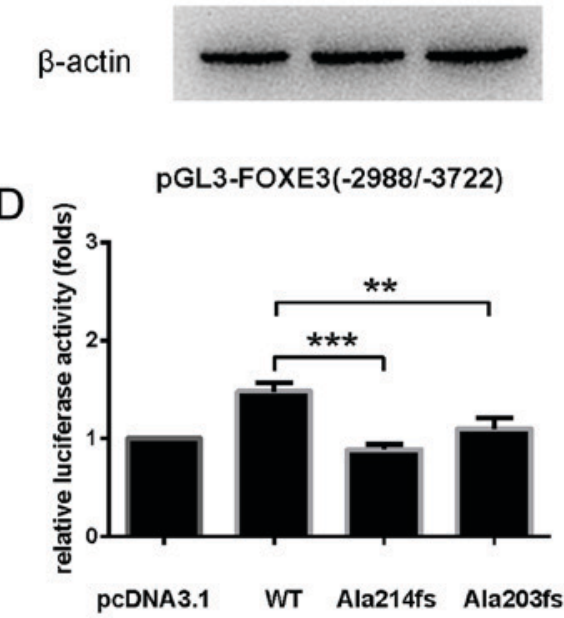

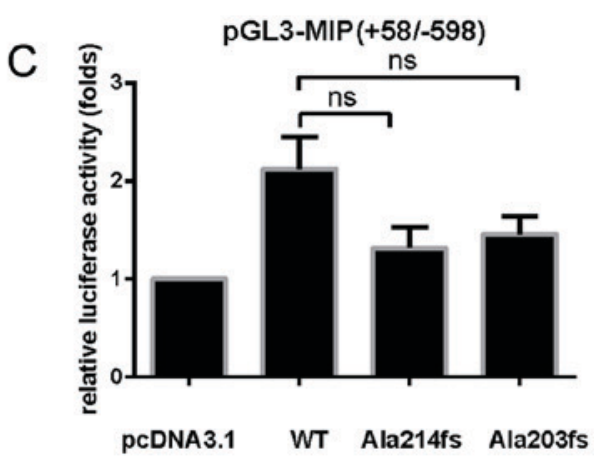

pGL3-LEMD2(-77/-985)

E

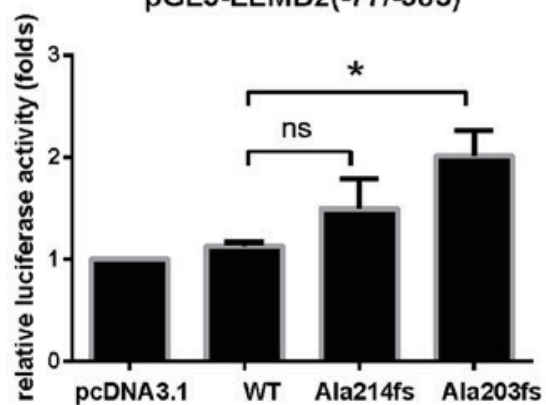

Figure 2. Functional analysis of the expression of PITX3 WT and mutants including. Subcellular localization and transactivation activity. (A) Subcellular localization of the PITX3 WT and mutant proteins transfected in HeLa cells. Cells were stained with PITX3 (N-20) primary antibody and Alexa Fluor 568 donkey anti-mouse IgG as a secondary antibody (red); DAPI was used as a nuclear counterstain (blue). Red fluorescence was not observed in HeLa cells without exogenous gene introduction. For cells transfected with PITX3 wild-type and mutants plasmids, the red fluorescence was localized predominantly in the nucleus. Western blot analysis indicated that the protein expression of PITX3 mutants was not affected. (B) Luciferase assay results for PITX3 WT and mutants co-transfected with the (C) pGL3-MIP (+58/-598), (D) pGL3-FOXE3 (-2988/-3722) or (E) pGL3-LEMD2 (-77/-985) reporters in 293T cells. All luciferase activities were normalized to $\beta$-galactosidase activity. In comparison with the empty vector pcDNA3.1, the values are indicated as fold changes of luciferase activity. ${ }^{*} \mathrm{P} \leq 0.05,{ }^{* *} \mathrm{P} \leq 0.01$ and ${ }^{* * *} \mathrm{P} \leq 0.001$. PITX3, paired like homeodomain 3; WT, wild-type; MIP, lens fiber major intrinsic protein; FOXE3, forkhead box protein E3; LEMD2, LEM domain-containing protein 2; ns, not significant.

Transactivation activity. To investigate the transcriptional activity of PITX3 WT and mutants in 293T cells, co-transfection assays were performed using the pGL3-MIP and pGL3-FOXE3 reporter constructs and the PITX3 WT and mutant expression plasmids. To isolate additional genes that are directly regulated by PITX3, a search for genomic sequences that contained evolutionarily-conserved bicoid/PITX3 binding sites in promoter regions and were located in the known cataract-associated genes was also performed. This identified the LEMD2 gene, which contains 2 tandem 'TAATCC' (bicoid binding site) repeats. Then, the pGL3-LEMD2 reporter gene plasmid was constructed to observe the expression change of pGL3-LEMD2 when co-transfected with PITX3 WT or mutant expression plasmids. The result of the western blot 
analysis indicated that the amount of protein of PITX3 WT and mutants were not different under visual observation (Fig. 2B. When PITX3 WT was co-transfected with the pGL3-MIP plasmid, a 2-fold increase in reporter gene activity was consistently observed compared with the empty vector (Fig. 2C). However, PITX3 mutants A214Rfs and A203Gfs co-transfected with the same reporter exhibited decreases of 38 and $31 \%$ in luciferase activity compared with the WT, respectively. A similar decrease in luciferase activity was observed when using the FOXE3-pGL3 reporter. As a $\sim 1.4$-fold increase in luciferase activity was detected when overexpressing PITX3 WT, the luciferase activity of the mutants A214Rfs and A203Gfs decreased by 40 and $26 \%$, respectively (Fig. 2D). By contrast, overexpression of PITX3 WT did not have any activation effect on LEMD2-pGL3. However, the A214Rfs and A203Gfs mutants exhibited increased transcriptional activity compared with the empty vector and PITX3 WT (Fig. 2E).

\section{Discussion}

$\mathrm{CC}$ is a clinically heterogeneous disease. It may occur in a variety of morphologic configurations: Total; nuclear; cortical; anterior subcapsular; and posterior subcapsular (11). Compared with other types of cataracts, posterior subcapsular cataract (PSC) is one of most common forms of cataract in clinical surgical series (12), but as a type of CC, it is unusual. At present, the PSC-associated genes include: Gap junction protein alpha 8; Ras related GTP binding A; PITX3; abhydrolase domain containing 12; charged multivesicular body protein 4B; crystallin beta B2; Beta-1,4-galactosyltransferase 7; ornithine aminotransferase; MAF; Unc-45 myosin chaperone B; and FYCO1 (13). PITX3 is one of PSC-causing genes, and there are 2 PITX3 mutations associated with PSC. Along with PITX1 and PITX2, PITX3 is the third gene in the PITX homeobox family and it is essential to the formation of the lens during eye development. There have been 9 PITX 3 mutations demonstrated to be associated with several different types of CC in several populations (7,14-23) (Table I). However, in China, there have been few studies on PITX3 mutations. In the present study, a wide-scale PITX3 mutation screening was implemented in $195 \mathrm{CC}$ families from 15 different provinces of China. Among them, 2 PITX3 mutations were identified in 3 CC families: One was a four-generation family with PITX3-c.608delC mutation causing PSC. A second mutation, (PITX3-c.640_656del) identified in two other families, resulted in a dominant and incompletely dominant inheritance pattern in these two families, respectively, which is different from the autosomal recessive inheritance pattern observed when the mutation was initially identified in a family from Saudi Arabia with ASD and severe congenital microphthalmia (7). The PITX3 protein has 2 domains: The conserved homeodomain is required for DNA binding (a lysine at residue 50 of the homeodomain interacts with base pairs 5 and 6 of the hexanucleotide consensus 5'-TAATCC-3') and the homeobox protein orthopedia, Aristaless related homeobox and Retinal homeobox protein Rx (OAR) domain is associated with target specificity and transactivation of PITX3 $(14,24)$. However, as the majority of PITX3 mutated sites identified are distributed in exon 4 of this gene, the N-terminal region of the
OAR domain is clearly a frequently mutated region. PITX3 deficiency results in a range of phenotypes, from isolated cataracts to microphthalmia in humans, and lens degeneration in mice (10). Although identification of downstream targets of PITX3 is vital for understanding the mechanisms of normal ocular development and human disease, these targets remain largely unknown. As a demonstrated target gene of PITX3, the expression of MIP is restricted to the lens. MIP is abundant in the lens fibers and distributed throughout the plasma membrane of the lens fiber cells, but it not present in the basal or lateral plasma membrane of the lens epithelial cells $(25,26)$, making it difficult to detect endogenous levels of MIP mRNA in other cell types. FOXE3 is an additional target gene of PITX3 in mice (27) and as it is conserved across mammalian species, direct PITX3 interaction with the consensus bicoid-binding site located upstream of FOXE3 gene may be additionally examined in humans. LEMD2 is a candidate target gene of PITX 3 as it has 2 tandem bicoid binding sites in the promoter and is associated with cataract disease (28). LEMD2 is involved in the regulation of several signaling pathways including mitogen-activated protein (MAP) kinase and protein kinase B, and serves a role in cell signaling and differentiation (29). The expression of LEMD2 has been demonstrated in the human whole lens (28). Previous study (30) has indicated that downregulation of mouse LEMD2 by RNA interference in myoblast cultures resulted in increased phosphorylation of MAP kinases extracellular signal-regulated kinase 1/2 (ERK1/2) and c-Jun $\mathrm{N}$-terminal kinase (JNK). ERK activation is required for lens fiber differentiation, and the upregulation of MIP at the transcriptional level was simultaneous with the activation of the fibroblast growth factor downstream signaling components, ERK1/2 and JNK (31). Therefore, PITX3 may negatively regulate LEMD2 to maintain fiber cell differentiation. Finally, a luciferase reporter assay was performed in the present study to examine the biological significance of PITX3 binding to the upstream bicoid sites of MIP, FOXE3 and LEMD2. As hypothesized, when PITX3 mutants were co-transfected with MIP-pGL3, a decrease in luciferase activity was observed compared with the PITX3 WT. The luciferase activity of the PITX3 mutants all decreased significantly in comparison with the PITX3 WT when co-transfected with FOXE3-pGL3. As a head-to-tail arrangement (5'-TAATCC... TAATCC-3') of bicoid elements is preferred over a head-to-head arrangement (5'-TAATCC... GGATTA-3') of bicoid elements $(27,32)$, the PITX3 WT and mutant sequences presented low levels of relative luciferase activity compared with pcDNA3.1, as the reverse complementary bicoid site GGATTA of FOXE3 may interact weakly with PITX3. However, when PITX3 WT and mutants were co-transfected with LEMD2-pGL3, the opposite effect was observed: When PITX3 WT was co-transfected with LEMD2-pGL3, almost no activation was observed. Conversely, the 2 PITX3 mutants exhibited an increased luciferase activity compared with the WT. The data is consistent with the hypothesis that PITX3 may negatively regulate LEMD2 in lens epithelial cells, promoting the activation of ERK, which is required for the differentiation of lens fiber cells. The alterations in the OAR motif may affect the target specificity of the homeobox-containing transcription factors that resulted in a decrease in the specific binding to its target genes and potentially enhanced the non-specific binding with 
Table I. Summary of 9 different mutations in PITX3 associated with cataract.

\begin{tabular}{|c|c|c|c|c|c|c|c|}
\hline Authors & $\begin{array}{l}\text { Nucleotide } \\
\text { change }\end{array}$ & $\begin{array}{l}\text { Amino acid } \\
\text { change }\end{array}$ & Inheritance & Origin & Type of cataract & Complication & (Refs.) \\
\hline \multirow{2}{*}{$\begin{array}{l}\text { Semina EV, } \\
\text { et al } 1998\end{array}$} & c. $38 \mathrm{G}>\mathrm{A}$ & p.S13N & $\mathrm{AD}$ & USA & Total cataract & - & (15) \\
\hline & c.640_656dup17bp & p.G220PfsX95 & $\mathrm{AD}$ & USA & Anterior cortical & ASMD & \\
\hline \multirow[t]{4}{*}{$\begin{array}{l}\text { Berry V, } \\
\text { et al } 2004\end{array}$} & c.640_656dup17bp & p.G220PfsX95 & $\mathrm{AD}$ & $\begin{array}{l}\text { Two separate } \\
\text { UK families }\end{array}$ & Posterior polar & ASMD & (18) \\
\hline & c.640_656dup17bp & p.G220PfsX95 & $\mathrm{AD}$ & China & Posterior polar & - & \\
\hline & c.650delG & p.G217AfsX91 & $\mathrm{AD}$ & UK & Posterior polar & - & \\
\hline & c.640_656dup17bp & p.G220PfsX95 & $\mathrm{AD}$ & Spain & Posterior polar & - & \\
\hline $\begin{array}{l}\text { Finzi S, } \\
\text { et al } 2005\end{array}$ & c.640_656dup17bp & p.G220PfsX95 & $\mathrm{AD}$ & USA & Posterior polar & - & (19) \\
\hline $\begin{array}{l}\text { Burdon KP, } \\
\text { et al } 2006\end{array}$ & c.640_656dup17bp & p.G220PfsX95 & $\mathrm{AD}$ & Australia & Posterior polar & - & (20) \\
\hline $\begin{array}{l}\text { Summers KM } \\
\text { et al } 2008\end{array}$ & c.640_656dup17bp & p.G220PfsX95 & $\mathrm{AD}$ & Australia & PSC & ASMD & (21) \\
\hline $\begin{array}{l}\text { Berry V, } \\
\text { et al } 2011\end{array}$ & c. $542 \mathrm{delC}$ & p.P181LfsX127 & $\mathrm{AD}$ & UK & Posterior polar & - & (16) \\
\hline $\begin{array}{l}\text { Aldahmesh MA, } \\
\text { et al } 2011\end{array}$ & , c.640_656del & p.A214RfsX42 & $\mathrm{AR}$ & Saudi Arabia & - & ASMD & (7) \\
\hline \multirow[t]{3}{*}{$\begin{array}{l}\text { Verdin } \mathrm{H} \text {, } \\
\text { et al } 2014\end{array}$} & c.573delC & p.S192AfsX117 & $\mathrm{AD}$ & $\begin{array}{l}\text { Belgo- } \\
\text { Romanian } \\
\text { family }\end{array}$ & Cataract & ASMD & (14) \\
\hline & c.640_656dup17bp & p.G220PfsX95 & $\mathrm{AD}$ & $\begin{array}{l}\text { Two separate } \\
\text { Belgian families }\end{array}$ & PSC & ASMD & \\
\hline & c.640_656dup17bp & p.G220PfsX95 & $\mathrm{AD}$ & $\begin{array}{l}\text { Two separate } \\
\text { Belgian families }\end{array}$ & $\begin{array}{l}\text { Posterior } \\
\text { polar }\end{array}$ & ASMD & \\
\hline $\begin{array}{l}\text { Bidinost C, } \\
\text { et al } 2006\end{array}$ & c.650delG & p.G217AfsX91 & $\mathrm{AD}$ & $\begin{array}{l}\text { Lebanese } \\
\text { family }\end{array}$ & $\begin{array}{l}\text { Posterior } \\
\text { polar }\end{array}$ & - & (22) \\
\hline \multirow{2}{*}{$\begin{array}{l}\text { Liu, H., } \\
\text { et al } 2017\end{array}$} & c.608delC & p.A203GfsX106 & $\mathrm{AD}$ & China & Cataract & & (17) \\
\hline & c.669delC & p.L225WfsX84 & $\mathrm{AD}$ & Iraq & Cataract & - & \\
\hline \multirow[t]{2}{*}{$\begin{array}{l}\text { Zazo Seco C, } \\
\text { et al } 2018\end{array}$} & c. $582 \mathrm{delC}$ & p.I194MfsX115 & & $\begin{array}{l}\text { North } \\
\text { Ireland }\end{array}$ & Cataract & - & (23) \\
\hline & c. $38 \mathrm{G}>\mathrm{A}$ & p.S13N & $\mathrm{AD}$ & France & - & - & \\
\hline Present study & $\begin{array}{l}\text { c.608delC } \\
\text { c.640_656del }\end{array}$ & $\begin{array}{l}\text { p.A203GfsX106 } \\
\text { p.A214RfsX42 }\end{array}$ & $\begin{array}{l}\mathrm{AD} \\
\mathrm{AD}\end{array}$ & $\begin{array}{l}\text { Chinese family } \\
\text { Two separate } \\
\text { Chinese families }\end{array}$ & $\begin{array}{l}\text { PSC } \\
\text { Cataract }\end{array}$ & $\begin{array}{l}\text { ASMD } \\
-\end{array}$ & \\
\hline
\end{tabular}

PSC, posterior subcapsular cataract; ASMD, anterior segment mesenchymal dysgenesis; AD, autosomal dominant.

other. Besides, the reason for the differences in luciferase activity between different PITX3 mutants may due to the fact that the destruction of OAR would not lead to a complete loss of PITX3 specificity, but a decrease in the specificity. In addition, the different affinity between PITX3 and its target genes may also lead to a range of luciferase activity levels when PITX3 WT and mutant plasmids are co-transfected with the promoter of different target genes. The nuclear localization of PITX3 WT and mutants may be attributed to the probable nuclear localization signal (RRAKWRK), which is located in the third helix of the PITX3 homeodomain and has been identified in several other homeodomain proteins (33-37). The pathogenic mechanism of CC from PITX3 mutations remains complicated, and it may be as follows: On one hand, the alteration of the OAR domain leads to a decrease in specific binding and targeting to target genes, which will affect the regular development of lens; conversely, by non-specific binding with other genes, certain genes should have been inhibited by PITX3, yet 
may be inactivated by interacting with PITX3 mutants and other genes, in particular genes containing bicoid binding sites, which may potentially also bind to PITX3 mutants. This may disrupt the development of other tissue development processes in the lens and lead to other phenotypes, including ASD.

In conclusion, the present study extended the mutation spectrum of PITX3 mutations in Chinese family with CC. In the first family, the disease-causing gene was identified by WES, but also detailed clinical images were obtained. The inheritance and phenotype caused by mutation p.A214RfsX42 observed in the present study was quite different from previous data. The functional analysis of these 2 PITX 3 mutations in the in vitro functional studies is an important complement and extension, which provides a potential interpretation for the pathogenesis and molecular mechanism of PITX3 mutations associated with CC.

\section{Acknowledgements}

Not applicable.

\section{Funding}

The present study was supported by the National Key Basic Research Program of China (973 Program; grant no. 2015CB964601), National Natural Science Foundation of China (grant nos. 81371062 and 31501014) and Thousand Youth Talents Program of China to Jianjun Chen.

\section{Availability of data and materials}

All data analyzed during the present study are included in this article, and the datasets are available from the corresponding author on reasonable request.

\section{Authors' contributions}

DM, BL, ZZho and JC were responsible for study design. CF, HZ, ZZho and JC collected the samples. ZW, JLi, XZ, SL, HZ and JLin performed the experiments. ZW, DM, HZ, ZZha, BL, ZZho and JC conducted data interpretation and analysis. ZW, DM,ZZho and JC were responsible for writing the manuscript. All authors have read and approved the final manuscript.

\section{Ethics approval and consent to participate}

Written informed consent was obtained from all participants including patients and their healthy family members, and the study was approved by the Institutional Review Board of the Tongji Eye Institute of Tongji University School of Medicine (Shanghai, China).

\section{Patient consent for publication}

Written informed consent was obtained from all patients and healthy volunteers.

\section{Competing interests}

The authors declare that they have no competing interests.

\section{References}

1. WHO. Visual impairment and blindness. 2014.http://www. who.int/mediacentre/factsheets/fs282/en/ Accessed May 14, 2016.

2. Liu YC, Wilkins M, Kim T, Malyugin B and Mehta JS: Cataracts. Lancet 390: 600, 2017.

3. Li FF, Zhu SQ, Wang SZ, Gao C, Huang SZ, Zhang M and Ma X: Nonsense mutation in the CRYBB2 gene causing autosomal dominant progressive polymorphic congenital coronary cataracts. Mol Vis 14: 750-755, 2008.

4. Zhong Z, Wu Z, Han L and Chen J: Novel mutations in CRYGC are associated with congenital cataracts in Chinese families. Sci Rep 7: 189, 2017.

5. Shiels A and Hejtmancik JF: Molecular genetics of cataract. John Wiley \& Sons, Ltd 37: 67, 2014.

6. Brémond-Gignac D, Bitoun P, Reis LM, Copin H, Murray JC and Semina EV: Identification of dominant FOXE3 and PAX6 mutations in patients with congenital cataract and aniridia. Mol Vis 16: 1705-1711, 2010.

7. Aldahmesh MA, Khan AO, Mohamed J and Alkuraya FS: Novel recessive BFSP2 and PITX3 mutations: Insights into mutational mechanisms from consanguineous populations. Genet Med 13: 978-981, 2011.

8. Kent WJ, Sugnet CW, Furey TS, Roskin KM, Pringle TH, Zahler AM and Haussler D: The human genome browser at UCSC. Genome Res 12: 996-1006, 2002.

9. Robinson JT, Thorvaldsdóttir H, Winckler W, Guttman M, Lander ES, Getz G and Mesirov JP: Integrative genomics viewer. Nat Biotechnol 29: 24-26, 2011.

10. Sorokina EA, Muheisen S, Mlodik N and Semina EV: MIP/Aquaporin 0 represents a direct transcriptional target of PITX3 in the developing lens. PLoS One 6: e21122, 2011.

11. Deng H and Yuan L: Molecular genetics of congenital nuclear cataract. Eur J Med Genet 57: 113-122, 2014.

12. Adamsons I, Muñoz B, Enger C and Taylor HR: Prevalence of lens opacities in surgical and general populations. Arch Ophthalmol 109: 993-997, 1991.

13. Shiels A, Bennett TM and Hejtmancik JF: Cat-Map: Putting cataract on the map. Mol Vis 16: 2007-2015, 2010.

14. Verdin H, Sorokina EA, Meire F, Casteels I, de Ravel T, Semina EV and De Baere E: Novel and recurrent PITX3 mutations in Belgian families with autosomal dominant congenital cataract and anterior segment dysgenesis have similar phenotypic and functional characteristics. Orphanet J Rare Dis 9: 26, 2014.

15. Semina EV, Ferrell RE, Mintz-Hittner HA, Bitoun P, Alward WL, Reiter RS, Funkhauser C, Daack-Hirsch S and Murray JC: A novel homeobox gene PITX3 is mutated in families with autosomal-dominant cataracts and ASMD. Nat Genet 19: 167-170, 1998.

16. Berry V, Francis PJ, Prescott Q, Waseem NH, Moore AT and Bhattacharya SS: A novel 1-bp deletion in PITX3 causing congenital posterior polar cataract. Mol Vis 17: 1249-1253, 2011.

17. Liu H, Liu H, Tang J, Lin Q, Sun Y, Wang C, Yang H, Khan MR, Peerbux MW, Ahmad S, et al: Whole exome sequencing identifies a novel mutation in the PITX3 gene, causing autosomal dominant congenital cataracts in a Chinese family. Ann Clin Lab Sci 47: 92-95, 2017.

18. Berry V, Yang Z, Addison PK, Francis PJ, Ionides A, Karan G, Jiang L, Lin W, Hu J, Yang R, et al: Recurrent 17 bp duplication in PITX 3 is primarily associated with posterior polar cataract (CPP4). J Med Genet 41: e109, 2004.

19. Finzi S, Li Y, Mitchell TN, Farr A, Maumenee IH, Sallum JM and Sundin O: Posterior polar cataract: Genetic analysis of a large family. Ophthalmic Genet 26: 125-130, 2005.

20. Burdon KP, McKay JD, Wirth MG, Russell-Eggit IM, Bhatti S, Ruddle JB, Dimasi D, Mackey DA and Craig JE: The PITX3 gene in posterior polar congenital cataract in Australia. Mol Vis 12: 367-371, 2006.

21. Summers KM, Withers SJ, Gole GA, Piras S and Taylor PJ: Anterior segment mesenchymal dysgenesis in a large Australian family is associated with the recurrent $17 \mathrm{bp}$ duplication in PITX3. Mol Vis 14: 2010-2015, 2008.

22. Bidinost C, Matsumoto M, Chung D, Salem N, Zhang K, Stockton DW, Khoury A, Megarbane A, Bejjani BA and Traboulsi EI: Heterozygous and homozygous mutations in PITX3 in a large Lebanese family with posterior polar cataracts and neurodevelopmental abnormalities. Invest Ophthalmol Vis Sci 47: 1274-1280, 2006. 
23. Zazo Seco C, Plaisancié J, Lupasco T, Michot C, Pechmeja J, Delanne J, Cottereau E, Ayuso C, Corton M, Calvas P, et al: Identification of PITX3 mutations in individuals with various ocular developmental defects. Ophthalmic Genet 39: 314-320, 2018.

24. Sakazume S, Sorokina E, Iwamoto Y and Semina EV: Functional analysis of human mutations in homeodomain transcription factor PITX3. BMC Mol Biol 8: 84, 2007.

25. Takata K, Matsuzaki T and Tajika Y: Aquaporins: Water channel proteins of the cell membrane. Prog Histochem Cytochem 39: $1-83,2004$

26. Gorin MB, Yancey SB, Cline J, Revel JP and Horwitz J: The major intrinsic protein (MIP) of the bovine lens fiber membrane: Characterization and structure based on cDNA cloning. Cell 39: 49-59, 1984.

27. Ahmad N, Aslam M, Muenster D, Horsch M, Khan MA, Carlsson P, Beckers J and Graw J: Pitx3 directly regulates Foxe3 during early lens development. Int J Dev Biol 57: 741-751, 2013.

28. Boone PM, Yuan B, Gu S, Ma Z, Gambin T, Gonzaga-Jauregui C, Jain M, Murdock TJ, White JJ, Jhangiani SN, et al: Hutterite-type cataract maps to chromosome 6p21.32-p21.31, cosegregates with a homozygous mutation in LEMD2 and is associated with sudden cardiac death. Mol Genet Genomic Med 4: 77-94, 2015.

29. Huber MD, Guan T and Gerace L: Overlapping functions of nuclear envelope proteins NET25 (Lem2) and emerin in regulation of extracellular signal-regulated kinase signaling in myoblast differentiation. Mol Cell Biol 29: 5718-5728, 2009.

30. Tapia O, Fong LG, Huber MD, Young SG and Gerace L: Nuclear envelope protein Lem 2 is required for mouse development and regulates MAP and AKT kinases. PLoS One 10: e0116196, 2015

31. Golestaneh, N, Fan J, Fariss RN, Lo WK, Zelenka PS and Chepelinsky AB: Lens major intrinsic protein (MIP)/aquaporin 0 expression in rat lens epithelia explants requires fibroblast growth factor-induced ERK and JNK signaling. J Biol Chem 279: 31813-31822, 2004.
32. Saadi I, Kuburas A, Engle JJ and Russo AF: Dominant negative dimerization of a mutant homeodomain protein in Axenfeld-Rieger syndrome. Mol Cell Biol 23: 1968-1982, 2003.

33. Moede T, Leibiger B, Pour HG, Berggren P and Leibiger IB: Identification of a nuclear localization signal, RRMKWKK, in the homeodomain transcription factor PDX-1. FEBS Lett 461: 229-234, 1999.

34. Hessabi B, Ziegler P, Schmidt I, Hessabi C and Walther R: The nuclear localization signal (NLS) of PDX-1 is part of the homeodomain and represents a novel type of NLS. Eur J Biochem 263: 170-177, 1999.

35. Kozlowski K and Walter MA: Variation in residual PITX2 activity underlies the phenotypic spectrum of anterior segment developmental disorders. Hum Mol Genet 9: 2131-2139, 2000.

36. Sabherwal N, Schneider KU, Blaschke RJ, Marchini A and Rappold G: Impairment of SHOX nuclear localization as a cause for Léri-Weill syndrome. J Cell Sci 117: 3041-3048, 2004.

37. Sabherwal N, Blaschke RJ, Marchini A, Heine-Suner D, Rosell J, Ferragut J, Blum WF and Rappold G: A novel point mutation A170P in the SHOX gene defines impaired nuclear translocation as a molecular cause for Léri-Weill dyschondrosteosis and Langer dysplasia. J Med Genet 41: e83, 2004.

cc) (1) (3) This work is licensed under a Creative Commons Attribution-NonCommercial-NoDerivatives 4.0 International (CC BY-NC-ND 4.0) License. 